CENTRO UNIVERSITÁRIO DE BRASÍLIA - UniCEUB

FACULDADE DE CIÊNCIAS DA EDUCAÇÃO E DA SAÚDE - FACES

PROGRAMA DE INICIAÇÃO CIENTÍFICA

MATEUS MEDEIROS LEITE

TREINAMENTO DE FORÇA EXCÊNTRICO E A PRODUÇÃO DE MARCADORES DE DANO MUSCULAR E MARCADORES INFLAMATÓRIOS EM MULHERES OBESAS.

BRASÍLIA-DF

2016 


\section{Unic:uB \\ Centro Unrversitb́no de Brasilıa}

\section{MATEUS MEDEIROS LEITE}

\section{TREINAMENTO DE FORÇA EXCÊNTRICO E A PRODUÇÃO DE MARCADORES DE DANO MUSCULAR E MARCADORES INFLAMATÓRIOS EM MULHERES OBESAS.}

Relatório final de pesquisa de Iniciação Científica apresentado à Assessoria de Pós-Graduação e Pesquisa pela Faculdade de Ciências da Educação e da Saúde - FACES.

Orientação: Alessandro de Oliveira Silva. 


\section{AGRADECIMENTOS}

Agradeço primeiramente a Deus por abrir as portas e me proporcionar esta oportunidade e me manter firme e de pé para realizar este trabalho.

Agradeço ao meu Pai e minha Mãe que sempre me apoiaram e me incentivaram a alcançar meus objetivos e me ensinaram o caminho certo a seguir. Agradeço a todos meus familiares, minha namorada, minha sogra, e meus amigos.

Agradeço aos Professores, Msc. Darlan Lopes de Farias, que no primeiro semestre do curso me mostrou que é possível sim chegar onde queremos. Este, que também me apresentou ao professor Dr. Alessandro de Oliveira Silva, meu orientador, que desde o início sempre foi um ótimo orientador e hoje o tenho não apenas como professor, mas como um amigo, que a cada dia me ajuda mais, me mostra o caminho a seguir e tenho certeza que ele é peça essencial para a concretização de vários objetivos que tenho na minha vida acadêmica. Agradeço também à sua esposa, professora Silvana Schwerz Funghetto, que foi fundamental para o desenvolvimento desta pesquisa. Agradeço ao professor Msc. Sergio Adriano Gomes, que vem me auxiliando durante toda esta caminhada, ajudando e incentivando diante de vários desafios que encontro. Agradeço também aos demais professores, que contribuíram, e por cada palavra de reconhecimento e incentivo.

Agradeço aos colegas de faculdade. Agradeço ao meu amigo, Vinícius Borges Vieira, que foi um irmão durante a realização desta pesquisa, sempre disposto a ajudar, correndo atrás e auxiliando em tudo. Agradeço a meu amigo, Arthur César Mees dos Santos pela força. Agradeço a aluna de Medicina e minha amiga Giovanna Pontes Guercio Spohr, que primeiramente elaborou este projeto de pesquisa com o professor, e que me auxiliou sempre quando eu precisei.

Agradeço ao pessoal dos laboratórios que disponibilizaram para realização da pesquisa. Agradeço ao pessoal da Assessoria do Programa de Iniciação Científica, Olívia, Clara, Karine, que sempre prestaram um bom trabalho, dispostas a tirar dúvidas, resolver pendências, correr atrás, por estarem ao nosso lado. Enfim, agradeço a todos, por me fazerem ter bons pensamentos e acreditar que sou capaz.

Filipenses 4:8- "Quanto ao mais, irmãos, tudo o que é verdadeiro, tudo o que é honesto, tudo o que é justo, tudo o que é puro, tudo o que é amável, tudo o que é de boa fama, se há alguma virtude, e se há algum valor, nisso pensai". 


\title{
TREINAMENTO DE FORÇA EXCÊNTRICO E A PRODUÇÃO DE MARCADORES DE DANO MUSCULAR E MARCADORES INFLAMATÓRIOS EM MULHERES OBESAS.
}

\author{
Mateus Medeiros Leite - UniCEUB, PIBIC-CNPq, aluno bolsista \\ mateus.edf@outlook.com
}

\begin{abstract}
Alessandro de Oliveira Silva- UniCEUB, professor orientador silva.alessandro.oliveira@gmail.com
\end{abstract}

Vinícius Borges Vieira - UniCEUB, colaborador vini9000@hotmail.com.com

\section{Silvana SchwerzFunghetto- UnB, professor colaborador} silvana.funghetto@gmail.com

\section{Darlan Lopes de Farias- UniCEUB, professor colaborador fariasdl@gmail.com}

$\mathrm{Na}$ atualidade, o sobrepeso e em especial a obesidade encontram-se associados a uma inflamação crônica, indicada pelo aumento dos marcadores inflamatórios, sendo que indivíduos nestas condições clínicas podem apresentar níveis séricos elevados de Interleucina-6 (IL-6), quando comparados com os níveis destes marcadores em indivíduos eutróficos. O objetivo do presente estudo foi investigar os níveis séricos do marcador inflamatório IL-6 e do marcador de dano muscular Creatina quinase (CK) antes e após o treinamento de força excêntrico (TFE) em idosas obesas. A presente pesquisa foi de caráter experimental e natureza quantitativa, realizada com 35 mulheres idosas (idade: 68,57 $\pm 6,81$ ) com excesso de massa adiposa e residentes em comunidade. Cada voluntária foi anteriormente ao início do programa de TFE, submetida à avaliação da composição corporal, através do exame de Absortometria Radiológica de Dupla Energia (DEXA), avaliação ortopédica seguida da fase de adaptação ao exercício e teste de 10 repetições máximas (10 RM). O TFE foi realizado na cadeira extensora de forma bilateral com $120 \%$ da carga máxima obtida no teste de 10 RM. A coleta da IL-6 foi realizada antes do início da sessão de TFE seguida de 0 hora, 3 horas, 24 horas e 48 após execução do exercício. A coleta da CK foi realizada antes e logo após o exercício, coletando sangue da veia ante cubital em tubos a vácuo. Os valores adotados para diferenças estatisticamente significativas através do Teste t pareado foi de $(p \leq 0,05)$. Os resultados de composição corporal indicaram (peso: 65,58 \pm 9,87; estatura: 1,53 \pm 0,06; \% gordura: $42,35 \pm 4,98)$. A concentração da CK nas condições préintervenção e pós-exercício foram significativamente diferentes (pré: $106 \pm 69,99 \mathrm{U} / \mathrm{l}$; pós: $120 \pm 86,26 \mathrm{U} / \mathrm{l} ; \mathrm{p}=0,02$ ). A produção do marcador inflamatório IL-6 apresentou diferença estatisticamente significativa apenas entre os níveis pré-exercício e no momento 0 hora após o exercício (pré: $3,82 \pm 3,98 \mathrm{pg} / \mathrm{ml}$; 0 hora: $2,97 \pm 2,79 \mathrm{pg} / \mathrm{ml}$; $p=0,05)$. Com isso os resultados apresentaram que o protocolo exercício de força excêntrico induziu aumentos na concentração de CK indicando dano muscular esquelético, e não exacerbação de IL-6 com diminuição em seus níveis pósexercício. Sendo assim, o treinamento de força excêntrico foi significativo para rompimento das fibras musculares e diminuição dos níveis inflamatórios logo após o exercício, indicando que seu efeito crônico, se periodizado e com uma boa recuperação, pode estar associado a ganhos de massa muscular esquelética e amenização do estado inflamatório em idosas obesas.

Palavras-chave: Treinamento de Força. Respostas Inflamatórias. Mulheres. 


\section{LISTA DE ABREVIATURAS}

(CK) - Creatina Quinase.

(DEXA)- Absortometria Radiológica de Dupla Energia.

(IL-6)- Interleucina 6.

(IL-1ß)- Interleucina1 beta.

(NPY)- Neuropepetídeo Y.

(PCR) Proteína C - Reativa.

(TFE)- Treinamento de Força Excêntrico.

(TNF- $\alpha$ ) Fator de Necrose Tumoral alfa.

(10 RM)- Teste de 10 Repetições Máximas.

(pg/ml)- Picograma por mililitro.

(U/I)- Unidade por litro. 


\title{
SUMÁRIO
}

\author{
INTRODUÇÃO 7 \\ FUNDAMENTAÇÃO TEÓRICA 8 \\ METODOLOGIA 9 \\ Local de realização da pesquisa 10 \\ Amostra 10 \\ Instrumentos e procedimentos metodológicos 10 \\ Avaliação da composição corporal 10 \\ Avaliação ortopédica 11 \\ Análise da IL-6 e CK $\quad 11$ \\ Procedimentos experimentais de Atividade Física12 \\ Fase de adaptação ao exercício 12 \\ Avaliação da força máxima (10 RM) 12 \\ Aplicação do TFE 12 \\ Análise estatística 13 \\ Preceitos éticos 13 \\ RESULTADOS E DISCUSSÃO \\ CONSIDERAÇÕES FINAIS 19 \\ REFERÊNCIAS 20
}




\section{INTRODUÇÃO}

Por muitos anos, o excesso de massa adiposa observada em indivíduos com sobrepeso e obesos, foi considerada como conseqüência de um balanço calórico positivo desencadeado por demasiada ingestão alimentar e falta de exercícios físicos. Entretanto, na atualidade, o sobrepeso e em especial a obesidade encontram-se associados a uma inflamação crônica, indicada pelo aumento dos marcadores inflamatórios, sendo que indivíduos nestas condições clínicas podem apresentar níveis séricos elevados de interleucina 6 (IL-6), interleucina 1 beta (IL-1ß), proteína C - Reativa (PCR) quando comparados comos níveis destes marcadores em indivíduos eutróficos (FANTUZZI, 2005).

Em mulheres idosas vem sendo relatadas modificações no sistema imunitário em decorrência do próprio envelhecimento, a denominada imunossenecência, e dentre essas alterações destaca-se o fenômeno de inflammaging, que se constitui em um processo inflamatório basal característico do envelhecimento e influenciado pela genética. $\mathrm{O}$ aumento da atividade inflamatória no idoso pode ser identificado pela elevação na produção e liberação de IL-6 e IL-1ß, dentre outras (MISHTO et al., 2003; GIUNTA, 2006; GOTO, 2008; TONET et al., 2008; MACEDO et al., 2009).

Sabe-se que o treinamento de força em indivíduos idosos melhora substancialmente a execução das atividades diárias, além do efeito positivo na massa muscular e óssea, especialmente nas idosas com excesso de peso. No entanto, o tipo e a intensidade do exercício prescrito podem levar a repercussões fisiológicas, bioquímicas, hormonais e inflamatórias bem distintas, sobretudo em mulheres idosas (CHODZKO-ZAJKO et al., 2009; STRASSER; SCHOBERSBERGER, 2010).

Neste sentido, existem várias diferenças entre ações musculares concêntricas e excêntricas, que durante o exercício oferece díspares estímulos ao sistema neuromuscular e repercutem de maneira distinta no organismo humano, fato que deve servir de fonte embasadora para a manipulação de variáveis durante a prescrição de atividades físicas (FISCHER, 2006; PETERSEN; PEDERSEN, 2006; PERDERSEN 2007). 
Estudos verificaram através da eletromiografia que ações excêntricas ativam um menor número de fibras musculares. Quanto menor for o número de unidades motoras recrutadas, maior será a força que cada unidade irá produzir, desta forma, a efetivação do movimento será realizada com uma menor estimulação neural, demonstrando assim que as ações excêntricas produzem uma maior eficiência neuromuscular (KRAMER et al., 2001; REMAUD; CORNU, 2005; DURAND et al., 2003; PURKAYASTH et al., 2006; SCHMITZ; WESTWOOD, 2001).

Com a prática do exercício, sobretudo exercício de força, as contrações musculares geram sinais que promovem a adaptação do músculo, e este exercício repetido diariamente produz efeito cumulativo e leva ao aumento dos valores e níveis de proteínas musculares responsáveis pela função muscular, ocorrendo assim - estímulo a síntese protéica. Neste sentido a CK pode ser utilizada como marcadores indiretos de dano muscular, que irá sinalizar e estimular a síntese protéica. (POWERS; HOWLEY, 2014; FOSCHINI et al., 2007)

Considerando o cenário exposto, cabe ressaltar a influência do TFE sobre o comportamento de parâmetros inflamatórios e de dano muscular induzido, e que contribuam para o monitoramento da efetividade e segurança desta prática, sobretudo em mulheres idosas com sobrepeso e/ou obesidade.

Portanto, o objetivo do presente estudo foi investigar os níveis séricos do marcador inflamatório IL-6 e do marcador de dano muscular CK antes e após o treinamento de força excêntrico em idosas obesas.

\section{FUNDAMENTAÇÃO TEÓRICA}

A IL-6 produzida durante a inflamação tem demonstrado ser uma importante ativadora do eixo hipotálamo-adrenal, levando a um aumento da produção de cortisol pelo córtex adrenal. O cortisol produzido em excesso é um importante fator de resistência a perda de peso, pois se ligará aos seus receptores no núcleo arqueado do hipotálamo, onde é produzida uma grande quantidade de neuropepetídeo Y (NPY), que é um potente estimulador da fome (MATSUDO et al., 2007).

No entanto, outros trabalhos não encontraram quaisquer diferenças entre os níveis plasmáticos da própria IL-6 a partir do genótipo. Além dos aspectos genéticos 
há de se considerar as modificações do sistema imunitário induzidas pelo exercício físico às quais vem sendo relatadas na literatura. Durante o exercício micro-lesões são causadas no músculo induzindo a produção de citocinas pró e antiinflamatórias (KUBASZEK et al., 2003, HENNINGSSON, et al., 2006; MERINO et al., 2007; TIDBALL, 2005).

A contração da fibra muscular produz e libera IL-6, primeira citocina presente na circulação durante o exercício, resultando em efeitos metabólicos assim como o aumento da circulação de lipídios, estimulando a lipólise, a oxidação de gordura, estando está citocina envolvida na homeostase da glicose no exercício. No entanto, a IL-6 precede o aparecimento de citocinas antiinflamatórias responsáveis por inibir citocinas pró-inflamatórias, sendo estas miocinas, produzidas pelo músculo esquelético, intimamente envolvidas na promoção da saúde. Por esse motivo o exercício físico apresenta importante papel sobre a proteção contra doenças associada a um estado inflamatório, assim como doenças cardiovasculares, diabetes tipo II, câncer entre outras síndromes metabólicas (FISCHER, 2006; PERDERSEN, 2007; STRASSER; SCHOBERSBERGER, 2011).

A associação entre obesidade e inflamação se dá pelo fato que o tecido adiposo em condições normais, tem a capacidade de sintetizar e armazenar lipídeos e também líber hormônios antiinflamatórios, porém estas também secretam outras citocinas inflamatórias, havendo uma inflamação de baixo grau. A IL-6 possui a característica pró-inflamatória quando secretada pelos adipócitos, dando-a o nome de Adipocina desencadeando a secreção de outras citocinas pró-inflamatórias como PCR e TNF- $\alpha$, e característica antiinflamatória quando secretada pelo músculo esquelético, dando-a o nome de Miocina, desencadeando a secreção de outras citocinas antiinflamatórias (GUSTAFSON, 2010; KAPLANSKI et al., 1994; BRANDT; PEDERSEN, 2011).

\section{METODOLOGIA}

A presente pesquisa teve caráter experimental e natureza quantitativa, realizada com mulheres idosas com excesso de massa adiposa e residentes em comunidade. As variáveis avaliadas foram caracterização da composição corporal, o 
modelo de treinamento excêntrico agudo, o marcador inflamatório IL-6 e o marcador de dano muscular CK.

\section{Local de realização da pesquisa:}

O projeto contou com apoio da universidade católica de Brasília (UCB) e da universidade de Brasília (UNB) que possuem a infra-estrutura ambulatorial no hospital da universidade católica de Brasília (HUCB) e no laboratório da faculdade de educação física da Universidade de Brasília, necessária à realização das análises clínicas das idosas e a aferição da composição corporal de cada voluntária da pesquisa por meio do método DEXA. O teste e o treino de força foram realizados no Laboratório de Estudos de Força disponibilizado pelo programa de Graduação em Educação Física.

\section{Amostra:}

Participaram do estudo 35 mulheres com idade de 60 anos ou mais e que atenderam aos seguintes critérios de inclusão: caracterizadas com sobrepeso ou obesidade detectado através de avaliação em DEXA, não estando em uso de terapia de reposição hormonal e de medicamentos que pudessem interferir nos níveis sanguíneos de citocinas, que não possuíssem problemas ortopédicos e articulares que impediam a realização da atividade física excêntrica ou que pudesse agravar o dano osteoarticular apresentado na avaliação ortopédica e funcional, e que concordassem em assinar o termo de consentimento livre e esclarecido. Foram excluídas aquelas que tinham menos de 60 anos de idade, que não apresentaram índice de massa corporal caracterizado como sobrepeso ou obesidade, estavam em uso de terapia de reposição hormonal e outros medicamentos que podiam interferir nos níveis sanguíneos de citocinas, as que possuíam alguns problemas ortopédicos e articulares nos membros inferiores e que não assinaram o termo de consentimento livre e esclarecido. 


\section{Instrumentos e procedimentos metodológicos:}

Os procedimentos para caracterização da amostra e aplicação dos critérios de inclusão e exclusão foram compostos por: avaliação da composição corporal, avaliação ortopédica, anteriormente ao início do programa de treinamento de força excêntrico.

Avaliação da composição corporal: A análise da composição corporal foi realizada por meio do DEXA. O exame foi realizado em equipamento da marca General Electric- GE, modelo 8548 BX1L, ano 2005, tipo Lunar DPX, com software programa Encore 2005, do Laboratório da Faculdade de Educação Física da Universidade de Brasília. Todas as avaliações foram realizadas pelo mesmo técnico, o qual era treinado para realização desses exames. Para executar o procedimento, as voluntárias retiraram todos os pertences de metais (pulseiras, brincos, anéis, aliança, etc.), posicionaram as participantes em decúbito dorsal sobre a mesa do equipamento, de forma que ficassem totalmente centralizadas em relação às laterais da mesa. As voluntárias foram instruídas a se disporem com os membros inferiores estendidos, sendo utilizada uma fita de velcro para manter os membros inferiores próximos e dar suporte aos pés, de forma que esses ficassem numa angulação de aproximadamente $45^{\circ}$ em relação ao plano vertical. Os membros superiores permaneciam estendidos e posicionados ao longo do corpo, sem que houvesse contato com o tronco.

Avaliação ortopédica: Foi realizada uma avaliação ortopédica e reumatológica por um fisioterapeuta para garantir a integridade do sistema músculo esquelético das participantes, bem como para certificar que o exercício excêntrico não seria prejudicial ou que alguma disfunção neste sistema interferiria no desempenho do mesmo.

Análise da IL-6 e CK: Antes e após iniciar a sessão de treinamento de forca excêntrico foi realizada a coleta de $25 \mathrm{ml}$ de sangue da veia ante cubital em tubos a vácuo para a realização das dosagens de citocinas. Todo o procedimento foi realizado por enfermeira devidamente treinada e conforme descritos a seguir:

- A determinação da IL-6 no sangue foi determinada pelo método ELISA, de acordo comas especificações do Kit de alta sensibilidade R\&D Systems Quantikine. Os resultados foram apresentados em $\mathrm{pg} / \mathrm{ml}$ em duplicata. $O$ 
coeficiente de variação intra-ensaio (CV), o CV inter- ensaio e a sensibilidade foram determinados.

- A determinação da CK no sangue foi determinada após o término da sessão, sendo coletada $5 \mathrm{~mL}$ de sangue $3 \mathrm{~h}, 24$ h e 48 h após o término do exercício, utilizando-se a metodologia cinético-espectrofotométrica.

\section{Procedimentos experimentais de Atividade Física:}

Antes de iniciar a execução do programa de exercício de força excêntrico, as voluntárias foram submetidas à fase de adaptação ao exercício e avaliação da força máxima, seguindo os procedimentos abaixo descritos:

- Fase de adaptação ao exercício: Por se tratar de uma população não praticante de exercícios regulares, as voluntárias foram submetidas a uma fase de adaptação ao exercício, para conhecerem de qual exercício se tratava e quais padrões adotados para a execução do mesmo.

- Avaliação de Força Máxima: Foram realizadas avaliações através do teste de 10 repetições máximas (10 RM) na cadeira extensora deforma bilateral seguindo de: aquecimento geral (10 minutos de esteira em intensidade leve), onde as voluntárias foram submetidas a oito repetições com $50 \%$ de 10 RM estimada de acordo com a capacidade de cada participante verificada na sessão de adaptação realizada nos dois dias anteriores, após um minuto de intervalo, foram realizadas três repetições com $70 \%$ de 10 RM estimada. Depois de três minutos as tentativas subseqüentes foram realizadas para uma repetição com cargas progressivamente mais pesadas até que a $10 \mathrm{RM}$ foi determinada em três tentativas, utilizando três minutos de descanso entre as tentativas. As padronizações das angulações e movimentos dos exercícios foram conduzidas de acordo com as descrições de Brown e Weir (2001). Para certificar que as 10 RM pré-treinamento foram ajustadas antes do início do treinamento a correlação intra- classe foi determinada entre a segunda e a terceira tentativa do teste de $10 \mathrm{RM}$. A maior 10 RM determinada a partir das últimas duas tentativas foi a utilizada como medida inicial.

- Aplicação do TFE: Após dois dias de descanso as voluntárias foram submetidas a uma série de aquecimento geral em cicloergômetro de 
membros inferiores durante 10 minutos a $60 \mathrm{rpm}$ e $50 \mathrm{w}$, seguido de aquecimento especifico de 10 repetições a $50 \%$ de 10 RM, com intervalo de 3 minutos no mesmo horário em que fizeram o treino de avaliação. A sessão de treino na cadeira extensora bilateral foi realizada $120 \%$ de $10 \mathrm{RM}$, somente na fase excêntrica, sendo a fase concêntrica executada pelo avaliador. Foram utilizadas sete séries de 10 repetições com descanso passivo de 3 minutos entre as séries e com intervalos de $15 \mathrm{~s}$ entre cada repetição de 2 segundos. O treino excêntrico foi adaptado de Willoughby e McFarlin (2003). As participantes do estudo foram orientadas a realizar a extensão dos joelhos mesmo que não conseguissem vencer a resistência.

\section{Análise Estatística}

Inicialmente os dados foram tratados a partir dos procedimentos descritivos, com as informações sendo processadas no pacote computacional Bioestat em sua versão 5.3. Medidas de tendência central e variabilidade dos dados foram representadas como média e desvio padrão. Foi utilizado coeficiente de correlação de Spearman e Teste t pareado para comparação dos valores pré e pós-exercício. $O$ nível de significância adotado foi de $(P \leq 0,05)$.

\section{Preceitos éticos}

Este projeto foi submetido ao Comitê de Ética em Pesquisa da Secretaria de Estado de Saúde do Distrito Federal e aprovado com o número de protocolo 035/2011.

\section{RESULTADOS E DISCUSSÃO}

Os dados de caracterização da amostra quanto à Idade, Força obtida no teste de 10 RM, e Composição Corporal realizada por meio do DEXA, estão indicados na Tabela 1 com média e desvio padrão. 
Tabela 1. Valores antropométricos e caracterização da amostra.

\begin{tabular}{cc}
\hline VARIÁVEIS & VALORES \\
\hline Idade (anos) & $68,57 \pm 6,81$ \\
\hline Teste 10 RM $\mathbf{( k g )}$ & $31,48 \pm 8,38^{*}$ \\
\hline Re-testes 10 RM $(\mathbf{k g})$ & $35,78 \pm 8,22^{*}$ \\
\hline Massa corporal $\mathbf{( k g )}$ & $65,58 \pm 9,87$ \\
\hline Estatura $(\mathbf{m})$ & $1,53 \pm 0,06$ \\
\hline IMC & $28,26 \pm 4,32$ \\
\hline \% Massa gorda & $42,35 \pm 4,98$ \\
\hline Massa magra $\mathbf{( k g )}$ & $37,82 \pm 5,02$ \\
\hline
\end{tabular}

*Nível de significância com $(p<0,05)$. IMC= Índice de Massa Corporal. 10 RM= 10 repetições máximas.

Os resultados no que diz respeito à coleta sanguínea para realização das dosagens de IL-6 pré- exercício, 0 hora, 3 horas, 24 horas e 48 horas após a execução do TFE e também para as dosagens de CK pré- exercício e 0 hora após o exercício, estão presentes na Tabela 2 com média e desvio padrão.

Tabela 2. Valores de concentrações sanguíneas pré e pós TFE.

\begin{tabular}{|c|c|}
\hline VARIÁVEIS & VALORES \\
\hline IL-6 Pré (pg/ml) & $3,82 \pm 3,98^{*}$ \\
\hline IL-6 0h (pg/ml) & $2,97 \pm 2,79^{*}$ \\
\hline IL-6 3h (pg/ml) & $3,90 \pm 3,53$ \\
\hline IL-6 24h (pg/ml) & $3,63 \pm 3,19$ \\
\hline IL-6 48h (pg/ml) & $3,35 \pm 3,46$ \\
\hline CK Pré (U/I) & $106,5 \pm 69,99^{*}$ \\
\hline CK Pós (U/I) & $120,1 \pm 88,26^{*}$ \\
\hline
\end{tabular}


A concentração da CK nas condições pré-intervenção e pós- exercício foram significativamente diferentes (pré: $106 \pm 69,99 \mathrm{U} / \mathrm{l}$; pós: $120 \pm 86,26 \mathrm{U} / \mathrm{l} ; \mathrm{p}=0,02$ ), indicando que o protocolo de TFE utilizado foi estimulante para rompimento das fibras musculares. Estudos indicam que níveis maiores em repouso de CK se apresentaram em idosas com síndrome metabólica quando comparadas a idosas sem síndrome metabólica, e tendo em vista os valores desta em como resposta de dano muscular ao exercício, a prescrição do treinamento de força deve adequar-se à individualidade do padrão imunológico, de dano muscular e respostas cardiovasculares a fim de minimizar os possíveis efeitos deletérios causados por um exercício acima das capacidades biológicas individuais (FARIAS et al., 2013; SOUSA et al., 2014).

No presente estudo não foi realizada a coleta de CK nos momentos 3 horas, 24 horas e 48 horas após a intervenção, o que poderia ter indicado a diminuição progressiva desses valores, mas mesmo assim, o protocolo utilizado indicou segurança para sua prescrição, pois os valores aqui observados estavam abaixo dos valores aceitos para rabdomiólise ou dano muscular de grande escala após TFE, que é de $1.000 \mathrm{U} / \mathrm{l}$ ou cinco vezes acima do limite normal superior (LIN et al., 2006). Corroborando com isto, em estudo realizado com idosas Tarja et al., (2014) foi identificado que idosas que melhor respondem ao exercício também apresentam aumento nos níveis de CK e IL-6, considerando que para a prescrição de exercício seja adotado um maior tempo para recuperação do dano muscular para esta população.

Considerando ainda as possíveis correlações entre o dano muscular e a resposta inflamatória, no presente estudo esta não foi identificada entre CK pós e IL-6 0 hora ( $r s=-0,13 ; p=0,43)$, porém como a coleta de CK não foi realizada também 3 horas, 24 horas e 48 após o TFE assim como a IL-6, não é possível se concluir se a resposta inflamatória seria decorrente do dano muscular, apesar de as médias de IL-6 3 horas, 24 horas e 48 horas serem maiores que na coleta 0 hora, estas apresentaram declínio progressivo, mas sem exacerbação. Porém, em estudo realizado por Pedersen e Hoffman-Goetz (2000), foi observado que o exercício de força induziu a aumentos de CK, porém não de IL-6, sugerindo que há a possibilidade de que a ampliação dos valores imediatos de IL-6 após o exercício talvez seja independente dos valores de CK. Porém Deuster et al., (2009) indicaram 
que aumentos nas concentrações de IL-6 podem estar associadas à regeneração muscular e resposta antiinflamatória ao dano causado pelo exercício.

Como apresentado na Tabela 2, quando tratados estatisticamente, os valores da produção do marcador inflamatório IL-6 apresentaram diferença significativa apenas entre os níveis pré- exercício e no momento 0 hora após o exercício (pré: $3,82 \pm 3,98 \mathrm{pg} / \mathrm{ml}$; pós- 0 hora: $2,97 \pm 2,79 \mathrm{pg} / \mathrm{ml} ; \mathrm{p}=0,05)$. A comparação dos valores de IL-6 pré com os valores pós 3 horas, 24 horas e 48 horas não apresentaram diferença estatisticamente significativa $(p=0,44 ; p=0,40 ; p=0,26)$ respectivamente, indicando não exacerbação de IL-6, havendo diminuição em seus níveis logo após o exercício.

Mesmo não havendo diferença estatística entre os valores pós: 3 horas, 24 horas e 48 horas, foi observado que os valores de IL-6 no momento 3 horas, após decréscimo dos valores de 0 hora em comparação aos níveis pré- exercício, foi maior que os valores pré- exercício e 0 hora, indicando assim um possível reparo do sistema imunológico ao estresse imposto pelo exercício indicado nos valores de CK pós- exercício. Foi observada uma mínima mudança nos valores das médias, na qual os valores 24 e 48 após o exercício permaneceram abaixo dos valores em repouso.

Estudo realizado com as mesmas variáveis determinando os níveis de CK e de IL-6 nos momento pré, 0 h, 3 h, 24 h, 48 horas pós treino excêntrico, porém com homens idosos e com objetivo de avaliar a relação do polimorfismo do gene promotor -174 C/G da IL-6 sobre as respostas da IL-6 sistêmica e dano muscular após treinamento de força excêntrico, identificou que diferenças entre os níveis de IL-6 basais e pós treino, concluindo que TFE influenciou na modulação de CK e IL-6 independentemente do Polimorfismo do gene promotor $-174 \mathrm{C} / \mathrm{G}$ da IL-6. (PEREIRA, 2013).

Assim como no presente estudo, porém utilizando mais variáveis, Funghetto et al., (2013), em estudo com objetivo de avaliar a relação de parâmetros inflamatórios (IL-6, IL-1 $\beta$, TNF- $\alpha$, proteína C reativa) com o Polimorfismo do gene promotor -174 C/G da IL-6, após o exercício de força excêntrico em mulheres idosas com obesidade, observou que houve uma associação entre o genótipo de IL-6 e os valores integrais de CK e IL-6 em resposta ao TFE. O protocolo de TFE, o mesmo adotado na presente pesquisa, indicou que este induziu ao dano muscular 
esquelético, sem exacerbação de IL-6, e valores de CK que foram medidos diferentemente do nosso estudo, que avalio apenas pré- intervenção e logo após. Com isto este protocolo para idosos foi considerado como um protocolo de segurança durante a prática clínica diária.

Petersen e Pedersen (2005) sinalizam que a IL-6 possui características ambíguas, quanto em ser marcador pró e antiinflamatório. Por isso, acredita-se que a diminuição nos níveis apresentados no presente estudo quando comparados aos valores de repouso, seja a diminuição geral (sistêmica) do estado inflamatório tendo em vista que a população era composta por idosas obesas. Porém neste mesmo estudo identificaram que o exercício induziu a liberação desta citocisa, desencadeando na liberação de outras citocinas antiinflamatórias como IL-10 e inibição da produção de TNF- $\alpha$.

Quanto ao TFE e as variáveis como intensidade e volume, no presente estudo foi utilizado de sete séries com 10 repetições e descanso passivo de 3 minutos entre as séries, com intervalos de $15 \mathrm{~s}$ entre cada repetição de 2 segundos. Com isso foi indicado através dos níveis de CK que este protocolo foi eficaz em produzir dano muscular, associada às respostas em um estado de recuperação pós- exercício para síntese protéica. (FOSS; KETEYIAN, 2000; POWERS; HOWLEY, 2014)

Em relação à produção de marcadores inflamatórios de acordo com na intensidade do exercício, Prestes et al., (2007) realizando estudo com ratos Wistar com objetivo de verificar os efeitos do exercício agudo sobre os números de leucócitos totais, linfócitos e citocinas circulantes, identificaram que a concentração de TNF- $\alpha$, caracterizada como citocina pró-inflamatória, diminuiu apenas com exercícios de intensidade moderada, já os níveis de IL-6 apresentou aumentos expressivos com exercício mais prolongado.

Em revisão realizada por Rosa e Batista (2005) foi exposto que além dos benefícios cardiovasculares, o treinamento de força tem a capacidade de modular a expressão elevada de citocinas pró-inflamatórias, como o TNF- $\alpha$ e IL-6, que estão associadas à insuficiência cardíaca crônica e a sua a progressão e deterioração clínica. Neste sentido, assim como apresentado neste estudo, o Treinamento de força pode atuar para diminuição do estado sistêmico inflamatório de pacientes e também como diminuição de possíveis eventos cardiovasculares que estão 
associados aos níveis destas citocinas pró-inflamatórias, tendo aplicação clínica, sendo o Treinamento de força como uma opção imunomodulatória.

Com isso, é conhecido que durante a realização do exercício, ocorre o rompimento de fibras musculares, ou micro-lesões induzindo a produção de marcadores de dano muscular como a CK e citocinas pró-inflamatórias e antiinflamatórias, assim como observado no presente estudo. Com isso, tem-se que o treinamento de força quando realizado regularmente, produzirá através da produção de marcadores antiinflamatórios, além de uma diminuição sistêmica do estado inflamatório, a reparação do dano muscular causado pelo exercício e conseqüentemente síntese protéica e melhora nos ganhos de força e massa muscular (TIDBALL, 2005; BAIRD et al., 2012; PETERSEN; PEDERSEN, 2006).

Assim, a investigação da utilização do TFE para população idosa é significantemente relevante, tendo em vista o acometimento de sarcopenia e diminuição na funcionalidade dos membros inferiores em idosas. Além dos benefícios aqui relatados, como diminuição do estado inflamatório geral, são bem conhecidos os diversos fatores influenciados com melhoras significativas através da prática de exercícios para a população idosa, como melhora no condicionamento cardiorrespiratório e integridade muscular, e redução nos sintomas depressivos e melhora na qualidade de vida relacionada à saúde (POWERS; HOWLEY, 2014; BRUNONI et al., 2015).

Cabe ressaltar as principais limitações do presente estudo, como o número reduzido de participantes, a falta de análise morfológica de lesão muscular, a não coleta dos valores de CK na mesma seqüência de IL-6, para comparação dos mesmos e possíveis correlações como indicados em alguns estudos citados acima, a adição de um grupo controle e a comparação com outras citocinas de características pró-inflamatórias e antiinflamatórias.

Próximos estudos utilizando mais variáveis de marcadores inflamatórios e de dano muscular são de extrema relevância para uma melhor visão das respostas sistêmicas ao TFE, assim como controle de variáveis genéticas e hormonais e suas possíveis influências nas respostas ao exercício. Estudos realizados com homens idosos utilizando os mesmos parâmetros também seriam interessantes, assim como utilização de grupos controles, grupo de idosos eutróficos e obesos, e um estudo 
com idosas eutróficas, utilizando o mesmo protocolo de exercício excêntrico para identificar as respostas inflamatórias.

\section{CONSIDERAÇÕES FINAIS}

O presente estudo demonstrou evidências que o treinamento de força excêntrico realizado com idosas contribuiu para diminuição do estado de inflamação sistêmica, com perfil inflamatório alterado devido à obesidade e ao fato da senescência. O protocolo de TFE utilizado foi eficaz para produção CK, marcador de dano muscular induzido pelo exercício, não havendo exacerbação nos seus valores, indicando segurança para utilização deste para prescrições com mulheres idosas obesas e diminuição do marcador inflamatório IL-6. Neste sentido, o treinamento de força excêntrico foi significativo para rompimento das fibras musculares e diminuição dos níveis inflamatórios logo após o exercício, mantendo baixo o estado inflamatório por até 48 horas após o exercício, indicando que seu efeito crônico, se periodizado e com uma boa recuperação, pode estar associado a ganhos de massa muscular esquelética, com reparo sistêmico a este dano, ou síntese protéica, e amenização do estado inflamatório em idosas obesas. 


\section{Referências}

BAIRD, M. F. et al. Creatine-kinase-and exercise-related muscle damage implications for muscle performance and recovery. Journal of nutrition and metabolism, $v$. 2012, 2012.

BRANDT, C.; PEDERSEN, B. K. The role of exercise-induced myokines in muscle homeostasis and the defense against chronic diseases. Bio Med Research International, v. 2010, 2010.

BROWN, L. E.; WEIR, J. P. Asep procedures recommendation i: accurate assessment of muscular strength and power. Professionalization of Exercise Physiology, v. 4, n. 11, 2001.

BRUNONI, L.et al. Treinamento de força diminui os sintomas depressivos e melhora a qualidade de vida relacionada a saúde em idosas.Revista Brasileira de Educação Física e Esporte, v. 29, n. 2, p. 189-196, 2015.

CHODZKO-ZAJKO et al. Exercise and Physical Activity for Older Adults; Medicine e Science in Sports e Exercise, v. 41, n. 7, p. 1510-1530, 2009.

DEUSTER, P. A. et al. Creatine Kinase Clinical Considerations: Ethnicity, Gender and Genetics. Uniformed services univ of the health sciences bethesda md dept of military and emergency medicine, 2009.

DURAND, R. J. et al. Hormonal responses from concentric and eccentric muscle contractions. Medicine and science in sports and exercise, v. 35, n. 6, p. 937-943, 2003.

FANTUZZI, G. Adipose tissue, adipokines, and inflammation. Journal of Allergy and Clinical Immunology, v. 115, n. 5, p. 911-919, 2005.

FARIAS, D.L. et al. Idosas com síndrome metabólica apresentam maior risco cardiovascular e menor força muscular relativa. Einstein (São Paulo), v. 11, n. 2, p. 174-179, 2013.

FISCHER, C. P. Interleukin- 6 in acute exercise and training: what is the biological relevance. Exerc immunol rev, v. 12, n. 6-33, p. 41, 2006.

FOSCHINI, D.; PRESTES, J.; CHARRO, M. A. Relação entre exercício físico, dano muscular e dor muscular de início tardio. Revista brasileira de cineantropometria e desempenho humano, v. 9, n. 1, p. 101-106, 2007.

FOSS, M. L.; KETEYIAN, S.J. Fox: bases fisiológicas do exercício e do esporte. Guanabara Koogan, 2000.

FUNGHETTO, S. S. et al. Interleukin-6-174G/C gene polymorphism affects muscle damage response to acute eccentric resistance exercise in elderly obese women. Experimental gerontology, v. 48, n. 11, p. 1255-1259, 2013. 
GIUNTA, S. Is inflammaging an auto [innate] immunity subclinical syndrome?. Immunity \& Ageing, v. 3, n. 1, p. 1, 2006.

GOTO, M. Inflammaging (inflammation+ aging): A driving force for human aging based on an evolutionarily antagonistic pleiotropy theory?. Aging, v. 23, p. 25, 2008.

GUSTAFSON, B. Adipose tissue, inflammation and atherosclerosis. Journal of atherosclerosis and thrombosis, v. 17, n. 4, p. 332-341, 2010.

HENNINGSSON, S. et al. Interleukin-6 Gene Polymorphism-174G/C Influences Plasma Lipid Levels in Women. Obesity, v. 14, n. 11, p. 1868-1873, 2006.

KAPLANSKI, G. et al. Interleukin-1 induces interleukin-8 secretion from endothelial cells by a juxtacrine mechanism. Blood, v. 84, n. 12, p. 4242-4248, 1994.

KRAEMER, W. J. et al. The influence of muscle action on the acute growth hormone response to resistance exercise and short-term detraining. Growth Hormone \& IGF Research, v. 11, n. 2, p. 75-83, 2001.

KUBASZEK, A. et al. The C-174G promoter polymorphism of the IL-6 gene affects energy expenditure and insulin sensitivity. Diabetes, v. 52, n. 2, p. 558-561, 2003.

LIN, H.; CHIE, W.; LIEN, H. Epidemiological analysis of factors influencing an episode of exertional rhabdomyolysis in high school students. The American journal of sports medicine, v. 34, n. 3, p. 481-486, 2006.

MACEDO, C.; GAZZOLA, J.M.; NAJAS, M. Síndrome da fragilidade no idoso: importância da fisioterapia. Arq Bras ciênc saúde, v. 33, n. 3, p. 177-84, 2008.

MERINO, D. G. et al. Effects of chronic exercise on cytokine production in white adipose tissue and skeletal muscle of rats. Cytokine, v. 40, n. 1, p. 23-29, 2007.

MATSUDO, S. M. M; MATSUDO, V. K. R. Atividade física e obesidade: prevenção e tratamento. Atheneu, 2007.

MISHTO, M.et al. Immuno proteasomes and immuno senescence. Ageing research reviews, v. 2, n. 4, p. 419-432, 2003.

PEDERSEN, B. K. IL-6 signalling in exercise and disease. Biochemical Society Transactions, v. 35, n. 5, p. 1295-1297, 2007.

PEDERSEN, B. K. Muscles and their myokines. Journal of Experimental Biology, v. 214, n. 2, p. 337-346, 2011.

PEDERSEN, B. K.; HOFFMAN-GOETZ, L. Exercise and the immune system: regulation, integration, and adaptation. Physiological reviews, v. 80 , n. 3, p. 1055-1081, 2000. 
PEREIRA, L. C. A influência do treinamento excêntrico nos níveis séricos de IL-6 e no polimorfismo-174C/G da IL-6. 2013.

PETERSEN, A. M. W.; PEDERSEN, B. K.The anti-inflammatory effect of exercise. Journal of applied physiology, v. 98, n. 4, p. 1154-1162, 2005.

PETERSEN, A. M. W.; PEDERSEN, B. K.The role of IL-6 in mediating the antiinflammatory. J Physiol Pharmacol, v. 57, p. 43-51, 2006.

POWERS, S.K.; HOWLEY, E.T. Fisiologia do exercício: teoria e aplicação ao condicionamento e ao desempenho. 8. ed. Barueri: Manole, 2014.

PRESTES, J.et al. Influência do exercício físico agudo realizado até a exaustão sobre o número de leucócitos, linfócitos e citocinas circulantes. Fitness \& performance journal, n. 1, p. 32-37, 2007.

PURKAYASTHA, S. et al. Surface electromyographic amplitude-to-work ratios during isokinetic and isotonic muscle actions. Journal of athletic training, v. 41, n. 3, p. 314, 2006.

REMAUD, A.; CORNU, C.; GUÉVEL, A. A methodologic approach for the comparison between dynamic contractions: influences on the neuromuscular system. Journal of athletic training, v. 40, n. 4, p. 281, 2005.

ROSA, L. F. B. P. C; BATISTA, M. L. Jr. Efeito do treinamento físico como modulador positivo nas alterações no eixo neuroimunoendócrino em indivíduos com insuficiência cardíaca crônica: Possível atuação do fator de necrose tumorala. Revista Brasileira de Medicina do Esporte, v. 11, n. 4, p. 238-242, 2005.

SCHMITZ, R. J.; WESTWOOD, K. C. Knee extensor electromyographic activity-towork ratio is greater with isotonic than isokinetic contractions. Journal of athletic training, v. 36, n. 4, p. 384, 2001.

SOUSA, V. T.et al. Influência do exercício de força sobre as respostas da creatina quinase, interleucina-6 e pressão arterial em mulheres idosas. 2014.

STRASSER, B.; SCHOBERSBERGER, W. Evidence for resistance training as a treatment therapy in obesity. Journal of obesity, v. 2011, 2010.

TAJRA, V. S. et al. Identification of high responders for interleukin- 6 and creatine kinase following acute eccentric resistance exercise in elderly obese women. Journal of Science and Medicine in Sport, v. 17, n. 6, p. 662-666, 2014.

TIDBALL, J. G. Inflammatory processes in muscle injury and repair. American Journal of Physiology-Regulatory, Integrative and Comparative Physiology, v. 288, n. 2, p. R345-R353, 2005.

TONET, A. C. et al. Association between the-174 G/C promoter polymorphism of the interleukin-6 gene and cardiovascular disease risk factors in Brazilian older 
women. Brazilian Journal of Medical and Biological Research, v. 41, n. 1, p. 47-53, 2008.

WILLOUGHBY, D. S.; MCFARLIN, B.; BOIS, C. Interleukin-6 expression after repeated bouts of eccentric exercise. International journal of sports medicine, $v$. 24, n. 01, p. 15-21, 2003. 